\title{
Histopathologic interpersonal overview of generalized pustular cutaneous reaction to Hydroxychloroquine (HCQ): New challenging clinical manifestation
}

\author{
ALIREZA GHANADAN ${ }^{1,2,3}$, ZAHRA NARAGHI ${ }^{1}$, KAMBIZ KAMYAB-HESARI $^{1}$, AZITA NIKOO $^{1}$, ZAHRA HALAJI $^{* *}$, MARYAM \\ $\mathrm{GHIASI}^{4}$, ROBABEH ABEDINI ${ }^{4}$, MONIREH MAZANDARANI ${ }^{5,6}$, ALI POURALI7, SEPEHR KHOSRAVI ${ }^{8,9}$, AZADEH \\ GOODARZI ${ }^{* 10}$ \\ ${ }^{1}$ Department of Dermatopathology, Razi Hospital, Tehran University of Medical Sciences, Tehran, Iran \\ ${ }^{2}$ Department of pathology, Cancer Institute, Imam Khomeini Hospital Complex, Tehran University of Medical Sciences, Tehran, Iran \\ ${ }^{3}$ Universal Scientific Education and Research Network (USERN), Tehran, Iran \\ ${ }^{4}$ Autoimmune Bullous Disease Center, Razi Hospital, Tehran University of Medical Sciences, Tehran, Iran \\ ${ }^{5}$ Department of General Medicine, Shahroud University of Medical Sciences, Shahroud, Semnan, Iran \\ ${ }^{6}$ Golestan University of Medical Sciences, Sayad Shirazi Hospital, Gorgan, Iran \\ ${ }^{7}$ Department of General Medicine, Guilan University of Medical Sciences, Rasht, Guilan, Iran \\ ${ }^{8}$ Student Research Center, School of Medicine, Iran University of Medical Sciences, Tehran, Iran \\ ${ }^{9}$ Universal Scientific Education and Research Network (USERN), Tehran, Iran \\ ${ }^{10}$ Department of Dermatology, Rasool Akram Medical Complex, Iran University of Medical Sciences, Tehran, Iran \\ Corresponding author*: Azadeh Goodarzi*; MD, Associate Professor, Department of Dermatology, Rasool Akram Medical Complex, Iran \\ University of Medical Sciences, Tehran, Iran, Address: Niayesh Street, Sattarkhan Avenue, Tehran, Iran, ORCID ID: 0000-0002-1249-4429,; \\ Email: goodarzi.a@iums.ac.ir \& azadeh_goodarzi1984@yahoo.com; Phone number: 02166514001 \\ ${ }^{* *}$ Co Corresponding author: Zahra Halaji. Autoimmune Bullous Disease Center, Razi Hospital, Tehran University of Medical Sciences, \\ Tehran, Iran
}

\begin{abstract}
Background: Pathologic examination of Acute Generalized Exanthematous Pustulosis (AGEP) and Pustular Psoriasis (PP) are similar. We encountered many patients with PP or AGEP who cannot be distinguished clinically, pathologically and based on disease course from each so we designed a comprehensive interpersonal histopathologic overview of these patients' samples.

Method: Histopathological data of 16 patients over 3.5 years were analyzed. Four pathologists separately reviewed specimens based on eighteen criteria (9 Epidermal and 9 Dermal). Severity score for each criterion was considered as to be $(0$ to $3+)$. We compared the final pathologic diagnosis with primary one.

Results: Neutrophilic and lymphocytic infiltration in dermis were seen in all cases of AGEP while intraepithelial pustules. Subcorneal and intraepithelial pustules, spongiosis, neutrophilic exocytosis, neutrophilic and lymphocytic infiltration in dermis were observed in all cases of PP. The most severe neutrophilic inflammation; acanthosis and neutrophilic or lymphocytic infiltration were seen in PP.

The authors of this study have been reported generalized pustular clinical presentations of patients have been taken $\mathrm{HCQ}$, and in the recent pandemic it is also one of the concerns that many studies have been focused (....). Conclusion: When primary histopathologic report is AGEP/PP overlap, clinical judgment is the best way to manage and it is more probable that the final diagnosis being PP. When only AGEP or PP is histopathologic diagnostic report, it is usually enough to make final diagnosis and appropriate management.

Key words: hydroxychloroquine, HCQ, generalized pustular cutaneous eruption, Pustular Psoriasis (PP), Acute Generalized Exanthematous Pustulosism, AGEP, Histopathological overview, pathology, review
\end{abstract}

\section{INTRODUCTION}

Pustular Psoriasis (PP) and Acute Generalized Exanthematous Pustulosis (AGEP) are the major considered diagnoses for patients with multiple tiny pustules on a background of skin erythema. A history of consumption of relevant medications within previous 96 hours before the onset of eruption, rapid healing after medication withdrawal and eruption amenable to treatment with topical or short courses of oral steroids are in favor of AGEP. While history of psoriasis or certain predisposing conditions requiring stronger treatments and a course of flare-up and remissions even after withdrawal of the causative agents favors PP.[1-9]

In the pathology of AGEP, there are spongiotic pustules in the subcorneal layer of epidermis, dermal edema and infiltration of mixed interstitial and mid-dermal perivascular neutrophils (predominant) and eosinophils. Necrotic keratinocytes and exocytosis of eosinophils may be seen. There are no tortuous or dilated blood vessels. In the pathology of PP, neutrophillic accumulation is predominant (usually surrounded by parakeratosis) in association with psoriatic acanthosis. Spongiotic pustules entitled microabscess of Kogoj and Munro, which are intensified pustules, can be seen in active psoriasis.

Severe edema of superficial dermis, necrosis of keratinocytes and exocytosis of eosinophils are more in favor of AGEP and acanthosis more in favor of PP.[10-14]

Based on the observation of multiple patients at Razi Hospital due to pustular reaction to Hydroxychloroquine (HCQ) who were not clinically fully compatible with either AGEP or PP providing the diagnosis for these cases are complicated. The histopathologic features of these cases were also inconsistent. Repeated biopsies were necessary for a better clinical judgment and management of these patients. Therefore, we designed a comprehensive 
interpersonal histopathologic overview of histopathologic features of these patients.

\section{PARTICIPANTS AND METHODS}

We had histopathological data of 16 patients with pustular drug reaction due to $\mathrm{HCQ}$ hospitalized at skin specialized Razi Hospital, Tehran, Iran, over3.5 years. Since 6 patients of 16 cases during hospitalization, in the sequential biopsies, had two different histopathological diagnoses, we reviewed total number of 22 samples as a unique histopathological analysis. Four pathologists separately reviewed 22 specimens with an individual code. For each code we choose one diagnosis based on the most votes, and 18 criteria were identified and reviewed for each sample, including 9epidermaland 9 dermal criteria. Severity score of zero to three $(0,1+, 2+, 3+)$ was considered for each criterion.

\section{RESULTS}

After histopathological interpersonal review, 4 samples were diagnosed with the AGEP, 10with PP, 5with psoriasis and2 with AGEP / drug reaction overlap and one was diagnosed with drug reaction. We compared the final pathologic diagnosis with the primary pathologic report.

Edema, inflammation, neutrophilic and lymphocytic infiltration in superficial, perivascular and interstitial dermis were seen in $100 \%$ of the AGEP cases, but no case of intraepithelial pustules and dyskeratosis were observed.

Subcorneal and intraepithelial pustules, edema and inflammation, spongiosis, neutrophilic exocytosis, neutrophilic and lymphocytic infiltration in dermis (located in superficial and perivascular area) were observed in $100 \%$ of cases of PP but no dyskeratosis wasobserved. The most severe neutrophilic inflammation, acanthosis and infiltration of neutrophils and lymphocytes were seen in the cases of PP. In all 22 samples, inflammation, lymphocyte infiltration, and superficial perivascular infiltration were also observed.

Moreover, there was Epidermal necrosis in 2samples, one in AGEP and another in AGEP / Drug overlap. One interface pattern seen in AGEP / Drug overlap. Detailed results of histopathological interpersonal review were summarized in table 1. Here, we have described 3 examples for better understanding of table contents.

Example 1: In the AGEP column and SCP row, the means of $50 \%$ indicates that SCP observed in $50 \%$ of samples with diagnosis of AGEP and the means of $15 \%$ indicates that $15 \%$ of all SCPs observed in the samples were related to AGEP, and its severity was $1+$ in all AGEPs.

Example 2: In PUS-PSO column and Spongiotic pustule row, the means of $100 \%$ indicates that Spongiotic pustule observed in $100 \%$ of samples with diagnosis of PP and the means of $59 \%$ indicates that $59 \%$ of the all Spongoitic pustules observed in the samples were related to PP and severity of it, were $3+a n d 2+$ in $60 \%$ and $40 \%$ of PP cases, respectively.

Example 3: In the PSO column and Acanthosis row, the means of $80 \%$ represents that Acanthosis observed in $80 \%$ of samples with diagnosis of PSO and the means of $22 \%$ representsthat $22 \%$ of all Acanthosis observed in the samples were related to PSO.

\section{DISCUSSION}

Generalized pustular reaction followed by HCQ has been reported before and could be prominent cause of AGEP[6, 7]; however, there are few reports about PP.[10, 14-16] In most cases, these reactions were severe and required systemic treatments relatively for a long time.[6-8, 10, 14]This is true for six patients of this study, too.

In the absence of history of psoriasis, it can be difficult to differentiate clinically between two diagnoses. Histopathological diagnosis can lead us to a more definite diagnosis ${ }^{10}$ which is important because the treatment and prognosis of these two diseases is different. Although the pathology of AGEP and PP has some similarities, there are some diagnostic keys[9, 12, 17-19]. Experience showed that pathological differentiation of AGEP from PP when the pustular reactions is followed by $\mathrm{HCQ}$ consumption, are more difficult compare to normal. This is also true for clinical differentiation therefore this study was designed in this base[20-24].

In conclusion, after summation the result of clinical and pathological diagnosis and final succeeded method of treatment, we found that when primary histopathologic report is AGEP/PP overlap, clinical judgment of dermatologist is the best way to manage the disease; however, PP would be more preferably the primary diagnosis. When primary histopathologic report is AGEP, it is usually enough to make a definite diagnosis which results in managing the disease in the best way because it is not consistent with the final result in which interpersonal overview and repeated biopsies are not needed. When primary histopathologic report is PP, it is enough to treat the patient and the primary and the final result of review are consistent with each other.[25-27]

\section{CONCLUSION}

The authors of this study have been reported generalized pustular clinical presentations of patients have been taken $\mathrm{HCQ}$, and in the recent pandemic it is also one of the concerns that many studies have been focused $[8,9,18$, 22, 23]

Acknowledgements: The authors would like to express their gratitude to the staff of the Rasool Akram Medical Complex Clinical Research Development Center (RCRDC) for their technical and editorial assistance.

Declarations of Interest: We declare no competing interests.

Funding: None

\section{REFERENCES}

1. Djennane M, Tablit I, Billhot M, Banal F. [Acute generalized exanthematic pustulosis induced by hydroxychloroquine: case report]. La Revue de medecine interne. 2010;31(3):e78.

2. Evans CC, Bergstresser PR. Acute generalized exanthematous pustulosis precipitated by hydroxychloroquine. J Am Acad Dermatol. 2004;50(4):650651.

3. Martins A, Lopes LC, Paiva Lopes MJ, Rodrigues JC. Acute generalized exanthematous pustulosis induced by hydroxychloroquine. Eur J Dermatol. 2006;16(3):317-318.

4. Paradisi A, Bugatti L, Sisto T, Filosa G, Amerio PL, Capizzi $R$. Acute generalized exanthematous pustulosis induced by 
hydroxychloroquine: three cases and a review of the literature. Clin Ther. 2008;30(5):930-940.

5. Park J-J, Yun SJ, Lee J-B, Kim S-J, Won YH, Lee S-C. A case of hydroxychloroquine induced acute generalized exanthematous pustulosis confirmed by accidental oral provocation. Ann Dermatol. 2010;22(1):102-105.

6. Saissi EH, Beau-Salinas F, Jonville-Bera AP, Lorette G, Autret-Leca E. [Drugs associated with acute generalized exanthematic pustulosis]. Ann Dermatol Venereol. 2003;130(6-7):612-618.

7. Sidoroff A, Dunant A, Viboud C, Halevy S, Bavinck JN, Naldi L, Mockenhaupt M, Fagot JP, Roujeau JC. Risk factors for acute generalized exanthematous pustulosis (AGEP)-results of a multinational case-control study (EuroSCAR). $\mathrm{Br} J$ Dermatol. 2007;157(5):989-996.

8. Seirafianpour F, Mozafarpoor S, Fattahi N, SadeghzadehBazargan A, Hanifiha M, Goodarzi A. Treatment of COVID19 with pentoxifylline: Could it be a potential adjuvant therapy? Dermatologic Therapy. 2020;33(4):e13733.

9. Sadeghzadeh-Bazargan A, Behrangi E, Goodarzi A. Cytokine storm and probable role of immunoregulatory drugs in COVID-19: a comprehensive review. Iranian Journal of Dermatology. 2020;23(Suppl. 1 (COVID-19)):13-18.

10. Friedman SJ. Pustular psoriasis associated with hydroxychloroquine. J Am Acad Dermatol. 1987;16(6):12561257.

11. Halevy S, Kardaun SH, Davidovici B, Wechsler J. The spectrum of histopathological features in acute generalized exanthematous pustulosis: a study of 102 cases. $\mathrm{Br} \mathrm{J}$ Dermatol. 2010;163(6):1245-1252.

12. Kardaun $\mathrm{SH}$, Kuiper $\mathrm{H}$, Fidler $\mathrm{V}$, Jonkman MF. The histopathological spectrum of acute generalized exanthematous pustulosis (AGEP) and its differentiation from generalized pustular psoriasis. I Cutan Pathol. 2010;37(12):1220-1229.

13. Vassallo C, Derlino F, Brazzelli V, D'Ospina RD, Borroni G. Acute generalized exanthematous pustulosis: report of five cases and systematic review of clinical and histopathological findings. G Ital Dermatol Venereol. 2014;149(3):281-290.

14. Welsch MJ. Acute pustular psoriasis complicated by leukocytoclastic vasculitis. J Drugs Dermatol. 2003;2(2):193197.

15. Mohamadi M, Goodarzi A, Aryannejad A, Fattahi N, Alizadeh-Khoei M, Miri S, Hekmat H, Payab M, Bodaghabadi $M$. Geriatric challenges in the new coronavirus disease-19 (COVID-19) pandemic: A systematic review. Medical Journal of the Islamic Republic of Iran. 2020;34:123.

16. Behrangi E, Hallaji Z, Ghiasi M, Abedini R, Ghanadan A, Khodashenas Z, Goodarzi A. Hydroxychloroquine-induced unusual generalized pustular cutaneous reaction as a new clinical entity: a case series. Immunoregulation. 2020;3(1):67-72
17. Atefi N, Behrangi E, Mozafarpoor S, Seirafianpour $F$, Peighambari S, Goodarzi A. N-acetylcysteine and coronavirus disease 2019: May it work as a beneficial preventive and adjuvant therapy? A comprehensive review study. Journal of research in medical sciences: the official journal of Isfahan University of Medical Sciences. 2020;25.

18. Najar Nobari N, Seirafianpour F, Mashayekhi F, Goodarzi A. A systematic review on treatment-related mucocutaneous reactions in COVID-19 patients. Dermatologic Therapy. $2021 ; 34(1):$ e14662.

19. Goodarzi A. A comprehensive review on COVID-19 infection and comorbidities of various organs. Acta Medica Iranica. 2021:4-14.

20. Nobari NN, Montazer F, Seirafianpour F, Goodarzi A. Histopathologic changes and cellular events of organs systems in COVID-19. Journal of Cellular and Molecular Anesthesia. 2021;6(1):81-88.

21. Kooranifar S, Sadeghipour A, Riahi T, Goodarzi A, Tabrizi S, Davoody N. Histopathologic survey on lung necropsy specimens of 15 patients who died from COVID-19: A large study from Iran with a high rate of anthracosis. Medical Journal of The Islamic Republic of Iran (MJIRI). 2021;35(1):481-490.

22. Najar Nobari $N$, Seirafianpour $F$, Dodangeh $M$, Sadeghzadeh-Bazargan A, Behrangi E, Mozafarpoor S, Goodarzi A. A systematic review of the histopathologic survey on skin biopsies in patients with Corona Virus Disease 2019 (COVID-19) who developed virus or drugrelated mucocutaneous manifestations. Experimental dermatology. 2021.

23. Sadeghzadeh-Bazargan A, Rezai $M$, Nobari NN, Mozafarpoor S, Goodarzi A. Skin manifestations as potential symptoms of diffuse vascular injury in critical COVID-19 patients. Journal of cutaneous pathology. 2021.

24. Ehsani AH, Mortazavi H, Balighi K, Hosseini MS, Azizpour A, Hejazi SP, Goodarzi A, Darvari SB. Changes in body mass index and lipid profile in psoriatic patients after treatment with standard protocol of infliximab. Acta Med Iran. 2016;54(9):570-575.

25. Seirafianpour F, Sodagar S, Pour Mohammad A, Panahi P, Mozafarpoor S, Almasi S, Goodarzi A. Cutaneous manifestations and considerations in COVID-19 pandemic: a systematic review. Dermatologic Therapy. 2020;33(6):e13986.

26. Nobari NN, Goodarzi A. Patients with specific skin disorders who are affected by COVID-19: what do experiences say about management strategies? A systematic review. Dermatologic Therapy. 2020;33(6):e13867.

27. Sadeghzadeh-Bazargan A, Behrangi E, Goodarzi A. Systemic retinoids in the COVID-19 era-are they helpful, safe, or harmful? a comprehensive systematized review. Iranian Journal of Dermatology. 2020;23(Suppl. 1 (COVID19)):9-12. 
(a)
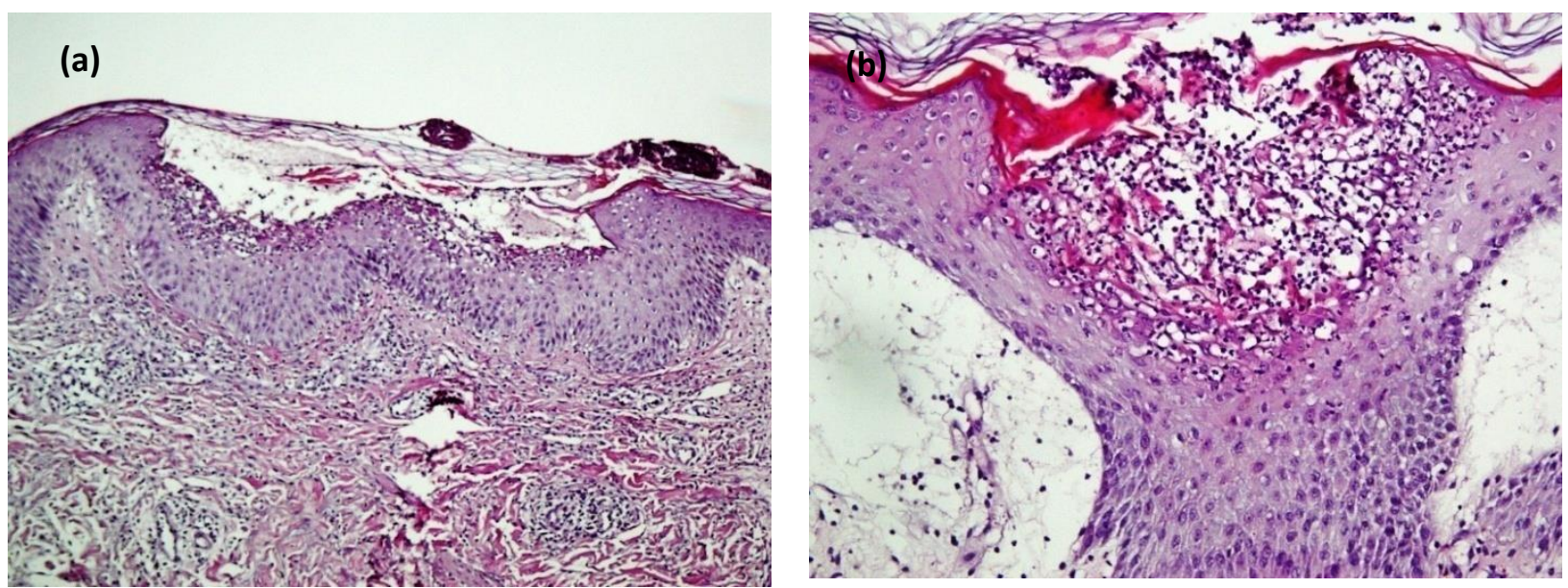

Figure 1: Part a: PUSTULAR PSORIASIS: Subcorneal and interacorneal neutrophilic pustules with epidermal acanthosis. Part b: ACUTE GENERALIZED EXANTHEMATOUS PUSTULOSIS: Subcorneal neutrophilic pustule with dermal edema and scattered eosinophils.

Table 1: pathologic findings of 22 samples from 16 patients (sev: severity, scp: subcorneal pustulosis, iep: interaepithelial pustulosis, spongiotic: spongiotic pustulosis, acanthosis: psoriatic hyperplasia, dyskeratosis, spongiosis, npara: neutrophilic parakeratosis, non-npara: non neutrophilic parakeratosis, neut-exocytosis: neutrophilic exocytosis, edema, neut: neutrophil, eos: eosinophil, lymph: lymphocyte, sup: superficial, mid:mid dermal, prevasc: prevascular, ints: interstitial, inflamation)

(Please interpret this table with regard to examples available in the part of results)

\begin{tabular}{|c|c|c|c|c|c|c|c|c|c|c|c|c|c|c|c|c|}
\hline \multirow{4}{*}{$\begin{array}{l}\text { TOTAL NUM=22 } \\
\text { PERCENT OF TOTAL }\end{array}$} & \multicolumn{3}{|l|}{ AGEP } & \multicolumn{3}{|c|}{ PSO-PUS } & \multicolumn{3}{|l|}{ PSO } & \multicolumn{3}{|c|}{ AGEP/DRUG } & \multicolumn{4}{|l|}{ DRUG } \\
\hline & \multirow{3}{*}{$\begin{array}{l}\text { NUM } \\
4 \% \\
18 \%\end{array}$} & \multirow{3}{*}{ SEV } & +1 & \multirow{3}{*}{$\begin{array}{l}\text { NUM } \\
10 \% \\
45 \%\end{array}$} & \multirow{3}{*}{ SEV } & +1 & \multirow{3}{*}{$\begin{array}{l}\text { NUM } \\
5 \% \\
23 \%\end{array}$} & \multirow{3}{*}{ SEV } & +1 & \multirow{3}{*}{$\begin{array}{l}\text { NUM } \\
2 \% \\
9 \%\end{array}$} & \multirow{3}{*}{ SEV } & +1 & \multirow{3}{*}{$\begin{array}{l}\text { NUM } \\
1 \% \\
5 \%\end{array}$} & \multirow{3}{*}{ SEV } & \multicolumn{2}{|c|}{+1} \\
\hline & & & +2 & & & +2 & & & +2 & & & +2 & & & \multicolumn{2}{|c|}{+2} \\
\hline & & & +3 & & & +3 & & & +3 & & & +3 & & & +3 & \\
\hline \multirow{7}{*}{ PUSTULE } & SCP & 2 & & 2 & \multirow{2}{*}{$\begin{array}{l}10 \\
77 \% \\
100 \%\end{array}$} & & 10 & & & & \multirow{2}{*}{$\begin{array}{l}1 \\
8 \% \\
50 \%\end{array}$} & & 1 & & & \\
\hline & 13 & $\begin{array}{l}15 \% \\
50 \%\end{array}$ & & & & & & & & & & & & & & \\
\hline & IEP & & & & 4 & & 4 & & & & & & & & & \\
\hline & & & & & $40 \%$ & & & & & & & & & & & \\
\hline & \multirow{3}{*}{$\begin{array}{l}\text { SPONGIOTIC } \\
17\end{array}$} & \multirow{3}{*}{$\begin{array}{l}3 \\
18 \% \\
75 \%\end{array}$} & & 2 & \multirow{3}{*}{$\begin{array}{l}10 \\
59 \% \\
100 \%\end{array}$} & & & \multirow{3}{*}{$\begin{array}{l}3 \\
18 \% \\
60 \%\end{array}$} & & 3 & \multirow{3}{*}{$\begin{array}{l}1 \\
5 \% \\
50 \%\end{array}$} & & 1 & & & \\
\hline & & & & 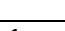 & & & 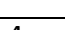 & & & & & & & & & \\
\hline & & & & & & & & & & & & & & & & \\
\hline \multirow{4}{*}{\multicolumn{2}{|c|}{$\begin{array}{l}\text { ACANTHOSIS } \\
18\end{array}$}} & \multirow{4}{*}{$\begin{array}{l}3 \\
17 \% \\
75 \%\end{array}$} & & & & & & & & & & & & & & \\
\hline & & & & 2 & & & 5 & & & 1 & & & & & & \\
\hline & & & & 1 & $50 \%$ & & 4 & $22 \%$ & & 2 & $11 \%$ & & 2 & & & \\
\hline & & & & & & & & & & 1 & & & & & & \\
\hline $\begin{array}{l}\text { DYSKERATOSIS } \\
4\end{array}$ & & & & & & & & $\begin{array}{l}2 \\
50 \%\end{array}$ & & 2 & $\begin{array}{l}1 \\
25 \%\end{array}$ & & 1 & $\begin{array}{l}1 \\
25 \%\end{array}$ & & 1 \\
\hline SPONGIOSIS & & $\begin{array}{l}4 \\
19 \%\end{array}$ & & 2 & $\begin{array}{l}10 \\
48 \%\end{array}$ & & 5 & $\begin{array}{l}4 \\
19 \%\end{array}$ & & 4 & $\begin{array}{l}2 \\
9 \%\end{array}$ & & 1 & $\begin{array}{l}1 \\
5 \%\end{array}$ & & \\
\hline 21 & & & & 2 & & & 5 & & & & & & 1 & & & 1 \\
\hline PARAKERATOSIS & & $\begin{array}{l}1 \\
8 \%\end{array}$ & & 1 & $\begin{array}{l}6 \\
46 \%\end{array}$ & & 5 & $\begin{array}{l}5 \\
38 \%\end{array}$ & & 4 & $\begin{array}{l}1 \\
8 \%\end{array}$ & & 1 & & & \\
\hline & 13 & & & & & & 1 & & & 1 & & & & & & \\
\hline & NON NPARA & $\begin{array}{l}1 \\
7 \%\end{array}$ & & 1 & $\begin{array}{l}7 \\
47 \%\end{array}$ & & 6 & $\begin{array}{l}5 \\
33 \%\end{array}$ & & 3 & $\begin{array}{l}2 \\
13 \%\end{array}$ & & 2 & & & \\
\hline & & $25 \%$ & & & $70 \%$ & & 1 & 100 & & 1 & $100 \%$ & & & & & \\
\hline & 15 & & & & & & & & & 1 & & & & & & \\
\hline NEUT-EXOCYTOSIS & & 2 & & 1 & 10 & & 2 & 1 & & & 1 & 2 & 1 & 1 & & 1 \\
\hline & & $50 \%$ & & & $100 \%$ & & 7 & $20 \%$ & & & & 2 & 1 & $100 \%$ & & \\
\hline
\end{tabular}




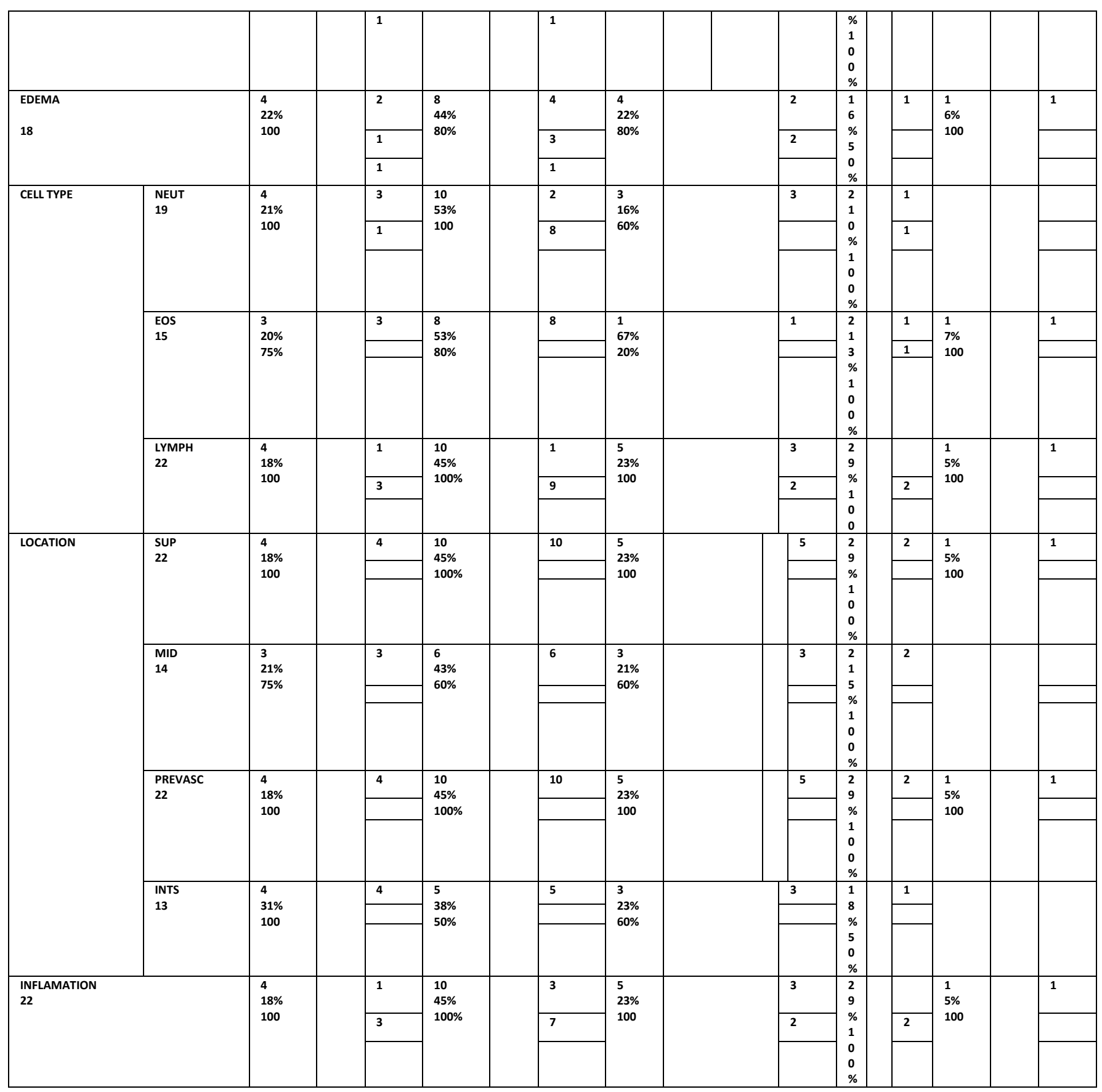

